\title{
Preliminary Waste Characterization Measurements in FiR 1 TRIGA Research Reactor Decommissioning Project
}

\author{
Räty, Antti
}

2018

Räty , A , Kekki , T , Tanhua-Tyrkko , M , Lavonen , T \& Myllykyla , E 2018 , ' Preliminary Waste Characterization Measurements in FiR 1 TRIGA Research Reactor Decommissioning Project ' , Nuclear Technology , vol. 203 , no. 2 , pp. 205-220 . https://doi.org/10.1080/00295450.2018.1445402

http://hdl.handle.net/10138/300719

https://doi.org/10.1080/00295450.2018.1445402

unspecified

acceptedVersion

Downloaded from Helda, University of Helsinki institutional repository.

This is an electronic reprint of the original article.

This reprint may differ from the original in pagination and typographic detail.

Please cite the original version. 
ANTTI RÄTY (antti.m.raty@helsinki.fi) ${ }^{1 *}$

TOMMI KEKKI (tommi.kekki@vtt.fi), ${ }^{2}$

MERJA TANHUA-TYRKKÖ (merja.tanhua-tyrkko@vtt.fi), ${ }^{2}$

TIINA LAVONEN (tiina.lavonen@vtt.fi),2

EMMI MYLLYKYLÄ (emmi.myllykyla@vtt.fi) ${ }^{2}$

${ }^{1}$ Department of Physics, University of Helsinki

Gustaf Hällströmin katu 2a, FI-00560 Helsinki, Finland

${ }^{*}$ Corresponding author

${ }^{2}$ Nuclear Safety, VTT Technical Research Centre of Finland Ltd.

P.O. Box 1000, FI-02150 Espoo, Finland

\section{PRELIMINARY WASTE \\ CHARACTERIZATION \\ MEASUREMENTS IN FIR1 TRIGA \\ RESEARCH REACTOR \\ DECOMMISSIONING PROJECT}

\section{TABLEOFCONIENIS}

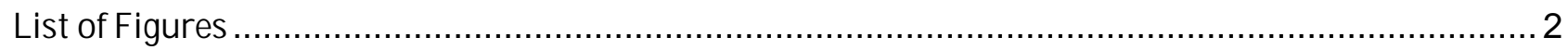

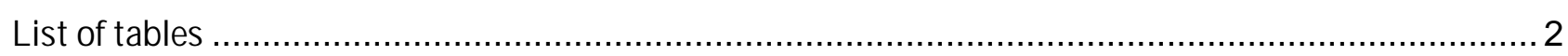

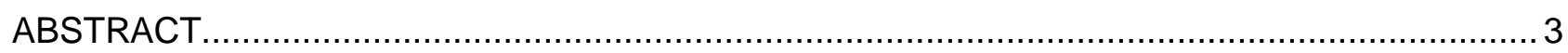

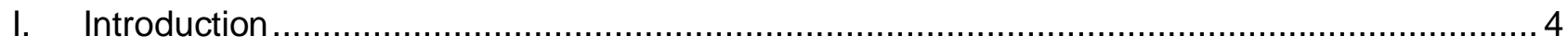

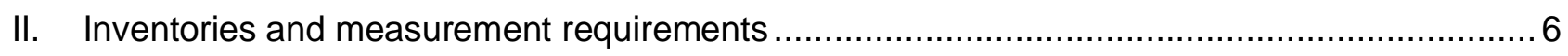

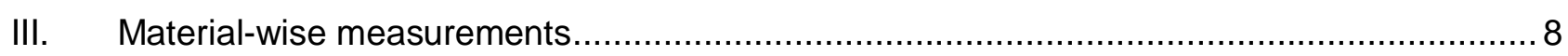

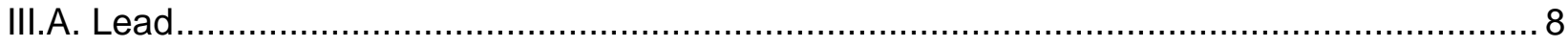

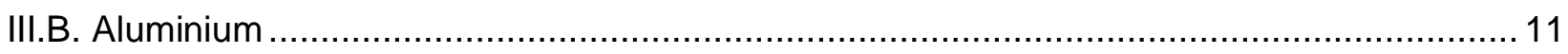

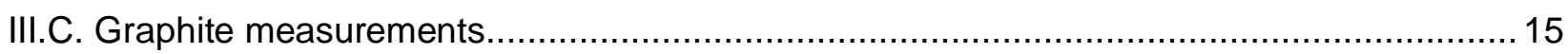

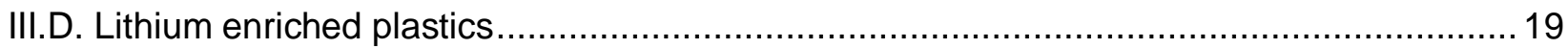

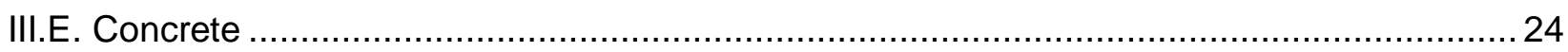

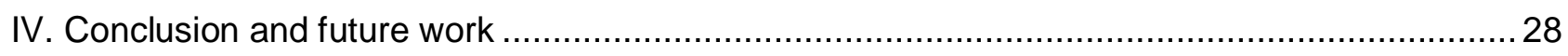

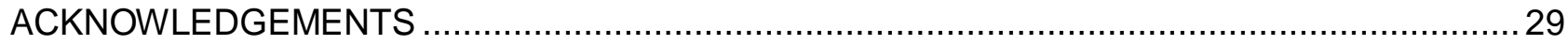




\section{LIST OF FIGURES}

Figure 1: Horizontal and vertical cross sections of the FiR 1 reactor. ....................................... 4

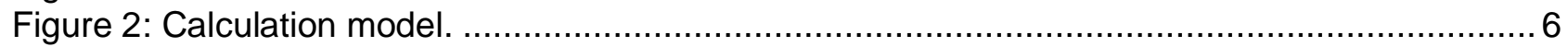

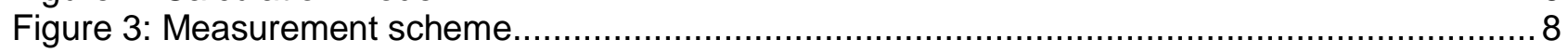

Figure 4: Location of the lead drilling holes marked with red color.......................................... 9

Figure 5: Aluminum parts in FiR1 reactor are illustrated in green color. .................................... 12

Figure 6: Measured gamma spectrum for aluminum. ....................................................... 15

Figure 7: Graphite in FiR1 reactor is illustrated on the right side of the core [7] ....................... 16

Figure 8: Operating principle of oxidizer device............................................................... 17

Figure 9: Calculated specific activities of C-14 in thermal column graphite as the function of

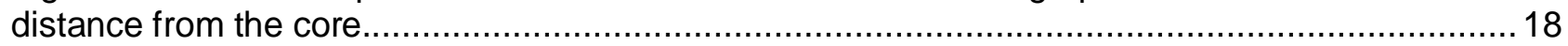

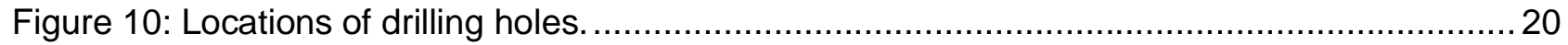

Figure 11: Schematic view of the oxidizer with retention of resulted HTO. QS- Oxygen supply; FM-

Flow-meter; TF (I/C)- Tube furnace (Incineration/Calcination); FC- Furnace controllers: TF (CO)-

Tube Furnace (Catalytic Oxidation); TQ- Quartz tube; S- Sample; CuO - CuO wire oxidation bed;

HTO RV - HTO Collector with 3 retention vials; C RV- Cryogenic retention vial, DwV -Dewar vessel RGM- Radioactive gas monitor, V RChB - ventilated Radiochemical Box .........................21

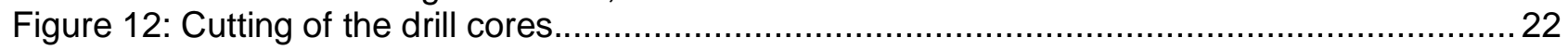

Figure 13: Temperature/time diagram applied for polyethylene/ $\mathrm{Li}_{2} \mathrm{CO}_{3}$ composite oxidation .........22 Figure 14: MCNP simulated total neutron fluence rates a) with thermal column and open beam ports, b) with thermal column and plugged beam ports, and c) with BNCT beam. [7] ..................24

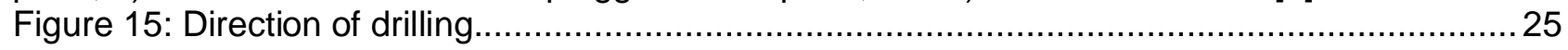

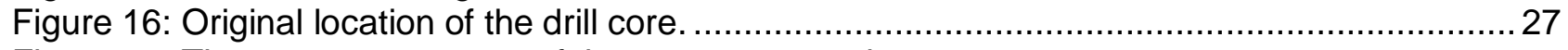

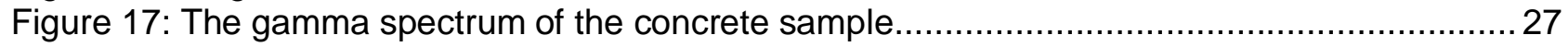

\section{LIST OFTABLES}

Table I: Material-wise total activities. Volumes are ideal quantities without taking into account

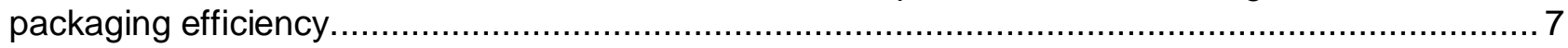

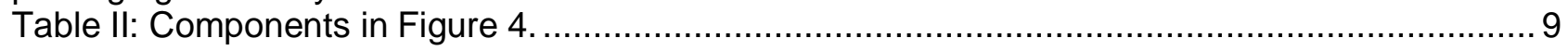

Table III: Measured impurities and relative standard deviations of lead in the BNCT station......... 10

Table IV: Comparison of measured and calculated gamma activities. Estimated measurement

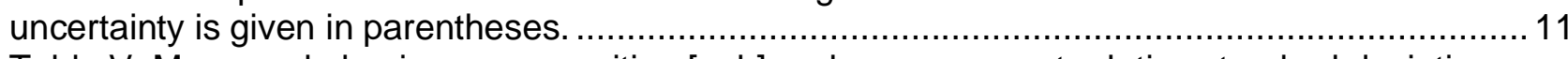

Table V: Measured aluminum composition [ppb] and measurement relative standard deviations

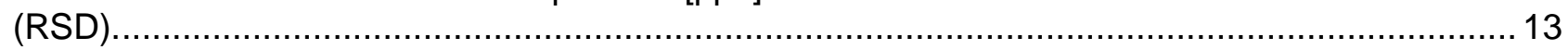

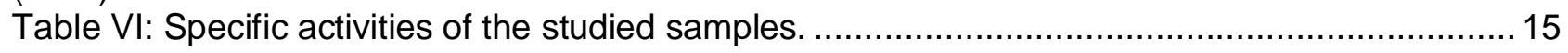

Table VII: Measured activities from samples 1-8........................................................... 18

Table VIII: Measured specific activities. Sample numbers refer to drilling locations in Figure 10...23

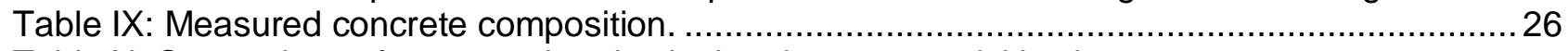

Table X: Comparison of measured and calculated gamma activities in concrete..........................28 


\section{ABSTRACT}

The objective of the study has been to verify the calculated residual activity in the decommissioning waste of TRIGA Mark II type research reactor FiR 1 in Finland. The knowledge of radioactive inventory of irradiated materials is important in the planning of the decommissioning activities and is essential for predicting the radiological impact to personnel and environment. Measurements are performed for low active material samples from outer parts of the reactor. Methods include gamma spectrometric measurements, composition measurements with mass spectrometry, oxidation measurements of especially C-14 in graphite and full combustion measurements of lithium enriched shielding materials. Results are compared to estimates calculated with a combined Monte Carlo model of the reactor and a point-depletion code modelling the irradiation history. Decommissioning waste consists mainly of ordinary concrete, aluminium, steel and graphite parts. Only preliminary measurements of low active samples are reported so far, but the same methods will be used later for characterizing and classifying dismantling waste. Some discussion of characterization requirements and future sampling is also included.

Keywords: decommissioning, TRIGA research reactor, activity inventory, characterization 


\section{INTRODUCTION}

FiR 1 is a $250 \mathrm{~kW}$ TRIGA Mark II open pool reactor from General Atomics that has been in operation in Espoo, Finland, for years 1962-2015. During its history FiR 1 has been used for training [1], scientific purposes [2], BNCT treatments [3] and isotope production [4].

The reactor is entirely above ground and is surrounded by a concrete shield structure, as shown in Figure 1. The reactor core and reflector assembly are located near the bottom of an aluminium tank 6.4 meters deep and 2.0 meters in diameter. Approximately 4.9 meters of demineralised water above the core provides vertical shielding. FiR 1 reactor has four beam tubes extending from the reflector assembly through the water and concrete to the outer face of the shield structure. These beam tubes have been used, for instance, to material research with neutrons during first decades of the FiR 1 operational history. The have been been plugged in the late 1980s'.

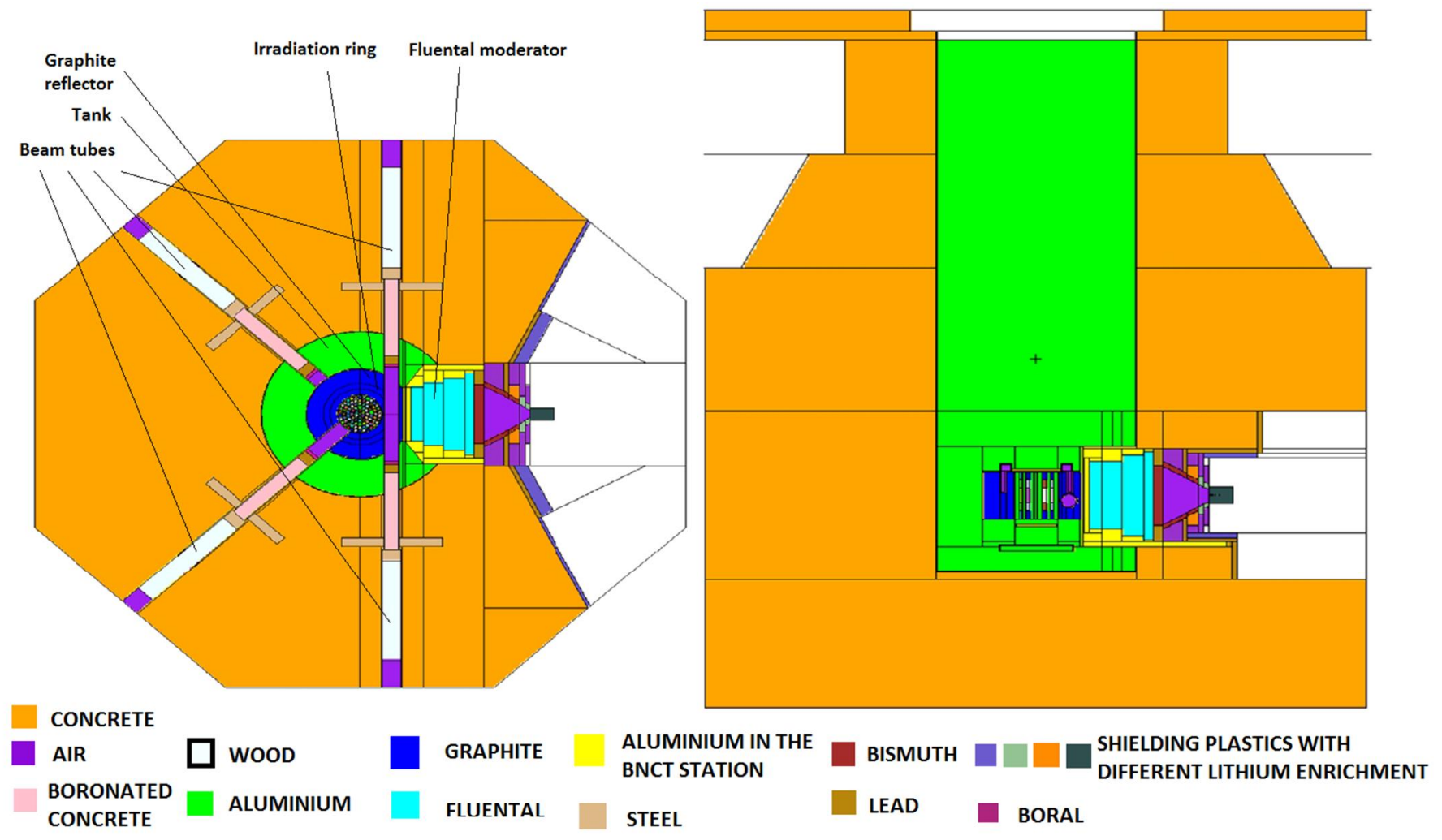

Figure 1: Horizontal and vertical cross sections of the FiR 1 reactor. 
Originally, FiR 1 reactor has had a 1.2×1.2x1.7 meters graphite thermal column extending from the outer surface of the reflector assembly and penetrating the reactor tank and shield structure. In 19951996, the thermal column was replaced by an epithermal boron neutron capture therapy (BNCT) beam [5]. A BNCT irradiation room was also built of steel tube elements filled with density-optimized heavy concrete and a heavy steel framed lead door. Based on the earlier shielding design calculations [6], it can be assumed that these structures are not activated, and it is justified to exclude them from current waste measurements. The BNCT beam moderator and collimator structures consist of several different materials, the most important of which is Fluental neutron moderator used to shape the neutron energy spectrum to suitable epithermal energy range for BNCT. Bismuth, lead and lithiated polyethylene are also used for gamma and neutron shielding.

FiR 1 reactor will be decommissioned in the following few years. Decommissioning planning requires knowledge on the activation levels and amounts of radioactive decommissioning waste to design safe dismantling procedures. Knowledge on the activity inventories of different waste streams are also important for appropriate waste packaging and planning both the interim storage and the final disposal of the decommissioning waste.

Computational estimates of the activity inventories were completed in 2016 [7]. This paper presents initial measurement results to verify earlier computational estimates. First general requirements and official regulations are introduced, then results of material-wise measurements are presented and finally the utilization of these results e.g. in active waste clearance procedures and other future work is discussed. 


\section{INVENTORIES}

AND

MEASUREMENT

\section{REQUIREMENTS}

Activity inventories of FiR 1 structures and components have been estimated in Reference [7]. In principle, activity inventory calculations require modelling of neutron fluxes for all the reactor structures and components with appropriate neutron transport code and combining these neutron flux values to material compositions and operating history in a suitable point-depletion code. An illustration following IAEA recommendation [8] is presented in Figure 2.

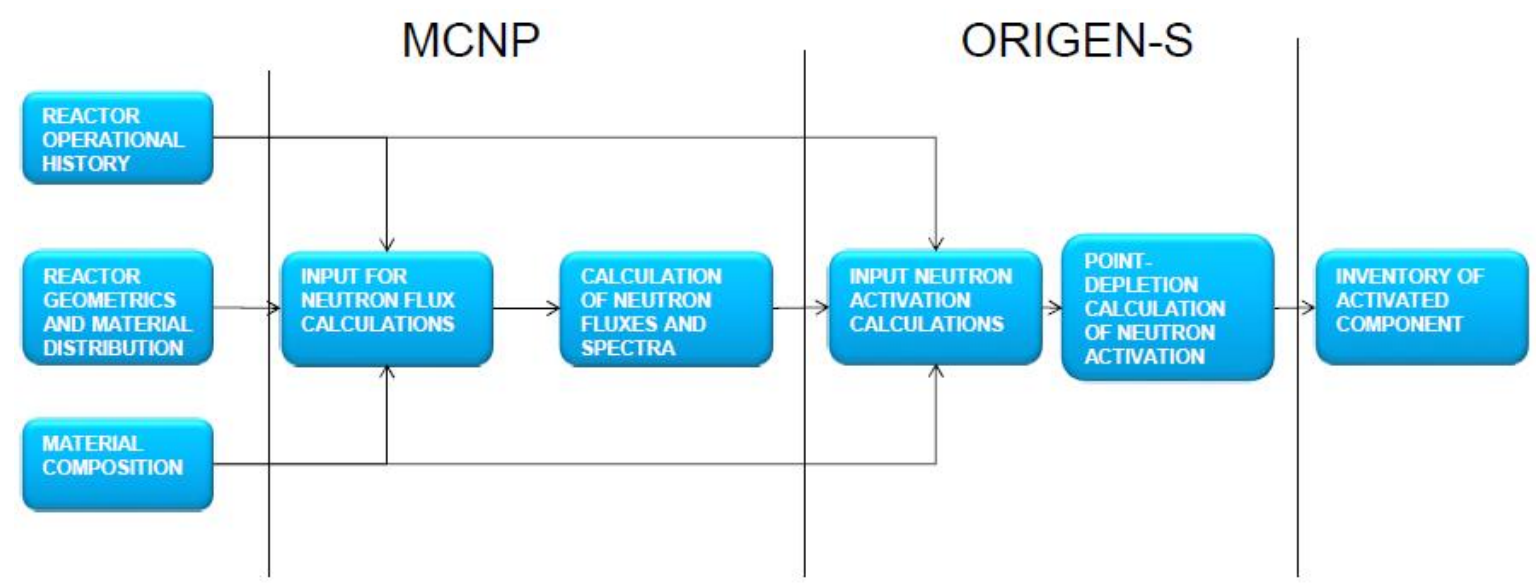

Figure 2: Calculation model.

Neutron fluence rates in FiR 1 reactor were calculated with the Monte Carlo code MCNP5 [9] using criticality eigenvalue search mode and cell-based tallies for all modelled structural components. Results per fission neutron were scaled to $250 \mathrm{~kW}$ nominal power and divided to three-group form as specified in ORIGEN-S manual. After calculating the fluxes in three-group form, they were used to model the decay chains of different nuclides in all the structures with the point-depletion code ORIGEN-S [10]. The irradiation history was modelled according to the reactor's actual operational history for years 1962-2015 taking into account all major reactor modifications (affecting the geometry and materials) during its history. After irradiation, a decay period was modelled to study the radionuclide inventory both during dismantling and final disposal. The total neutron flux was considered constant during all irradiations and zero in between them. Altogether, FiR 1 has generated around $11500 \mathrm{MWh}$ of thermal energy. 
ORIGEN-S calculations were performed on component or structure base resulting in around 200 output files.

Technically FiR1 contains several types of aluminium and steel from different manufacturers. This taken into account in the component-wise inventory calculations and detailed results will be used during practical dismantling work. Material-wise total values are presented in Table I to give an overview of the material quantities in the project.

Table I: Material-wise total activities. Volumes are ideal quantities without taking into account packaging efficiency.

\begin{tabular}{|l|lllll|}
\hline Material & Volume (m3) & Mass (tons) & Main isotopes & $\begin{array}{l}\text { Total activity } \\
\text { (TBq) }\end{array}$ \\
\hline Concrete & 25 & 61 & H-3, Eu-152, Co-60, C-14 & 0.1 \\
\hline Graphite & 2.6 & 4.4 & H-3, C-14, Eu-152, Eu-154 & 0.46 \\
\hline Steel & 0.4 & 3.5 & Fe-55, Ni-63, Co-60 & 1.91 \\
\hline Aluminium & 0.8 & 2.2 & Zn-65, Co-60, Ni-63 & 0.39 \\
\hline Fluental & 0.45 & 1.3 & H-3 & 1.3 \\
\hline Other & 10 & 2.7 & H-3, C-14, Ni-63 & 0.4 \\
\hline
\end{tabular}

The main sources of error in the used inventory calculation system are that diffusion of gaseous nuclides, e.g. $\mathrm{H}-3$, cannot be taken into account. Another source of error is that if exact material specification are not available, initial compositions are partially based on assumptions. Because activity is usually due to small impurities in materials, even low concentrations of, e.g., cobalt, nickel, europium, or zinc may have a notable effect on total activities. This was taken into account by assuming conservatively high impurities, but results will be verified with systematic measurements before and during the dismantling work. Eventually the total activity and nuclide vector for each waste package must be known. Both gamma and beta active nuclides are relevant. Gamma activities are relatively easy and fast to measure, but measuring beta activities requires chemical separation and different techniques such as liquid scintillation counting (LSC), mass spectroscopy etc. According to Finnish regulatory guides for nuclear and radiation safety [11], a scaling matrix approach is used. This means that before actual dismantling, material samples of each (plausibly) activated material are collected and studied in detail. Later, when actual waste packages are studied, only fast non-destructive measurements (gamma spectrometry) are performed and the earlier data is used to scale the hard-to-measure beta activities assuming the same ratio between nuclide-wise activities as in the samples. The procedure is further illustrated in Figure 3. 


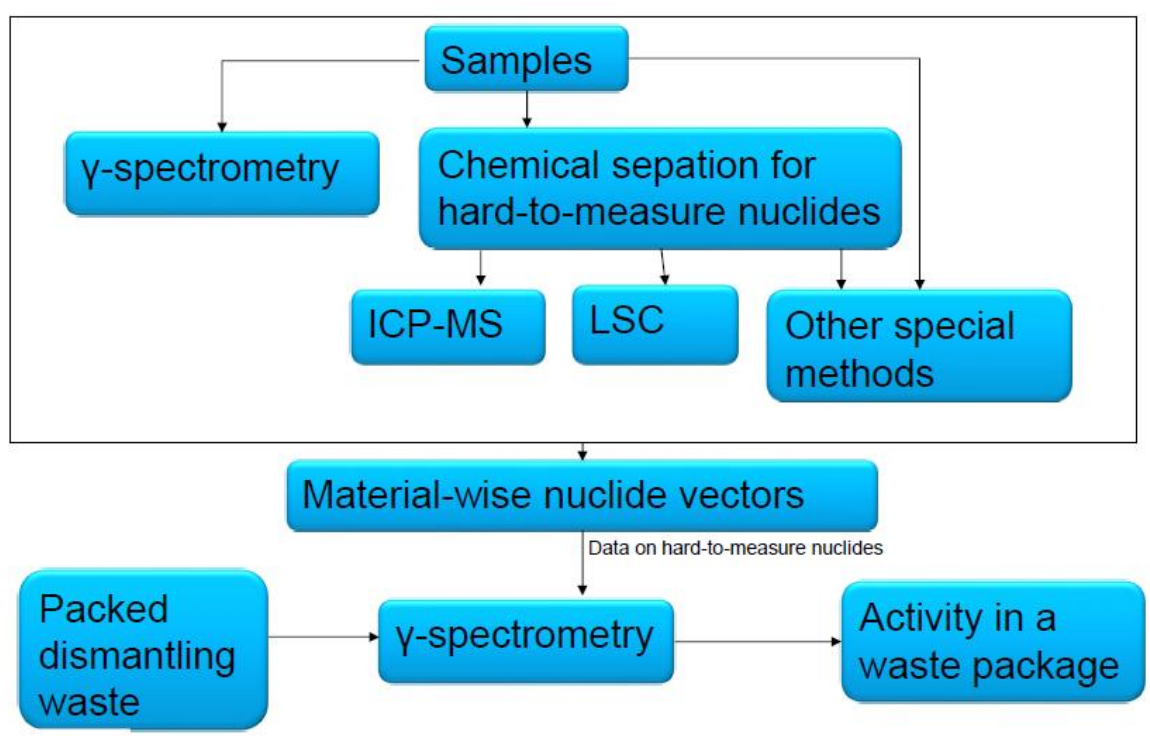

Figure 3: Measurement scheme

The gamma active nuclides that are used in scaling are called key nuclides. Identifying appropriate key nuclides requires considering their half-life, radiation energy, chemical challenges in the final disposal, toxicity etc. with a conservative approach, but also enabling the measurements to be performed later systematically for dozens of waste packages during dismantling. VTT uses In Situ Object Counting System (ISOCS) equipment by CANBERRA [12] for gamma spectrometric measurement. It is based on a liquid nitrogen cooled HPGe detector and spectroscopy software GENIE2000 [13]. Sourceless detector-specific calibrations are generated by using ISOCS software.

At the early stage of the project, the main restriction to sampling is that the structural integrity of the reactor must be maintained strictly. Consequently, this report mostly studies only low-active samples from the edges of the reactor. This helps to develop later a more detailed and logically optimized sampling and measurement plan.

\section{III.MATERIAL-WISE MEASUREMENTS}

\section{III.A. LFAD}

Lead has been used as a shielding material in the BNCT station of FiR1 reactor. Very pure (e.g. almost antimony-free) lead material was originally chosen for BNCT station shielding. Lead has been 
exposed to a neutron flux of around $10^{8} \mathrm{n} / \mathrm{s} \times \mathrm{cm}^{2}$ for years $1997-2015$ and according to inventory calculations, it is expected to have a very low specific activity of less than $10 \mathrm{~Bq} / \mathrm{g}$. Main contributing nuclides are Ag-110M, Ag-108, Co-60 and Cr-51.

Samples of lead were collected from BNCT station shielding materials. Drilling holes were chosen such that the distance of the samples from the BNCT station neutron channel is the same thus representing redundant parallel samples. Drilling locations are presented in Figure 4 with red color. The figure also lists some of the main components in the BNCT station with numbers 1-10. They have been labelled in Table II.

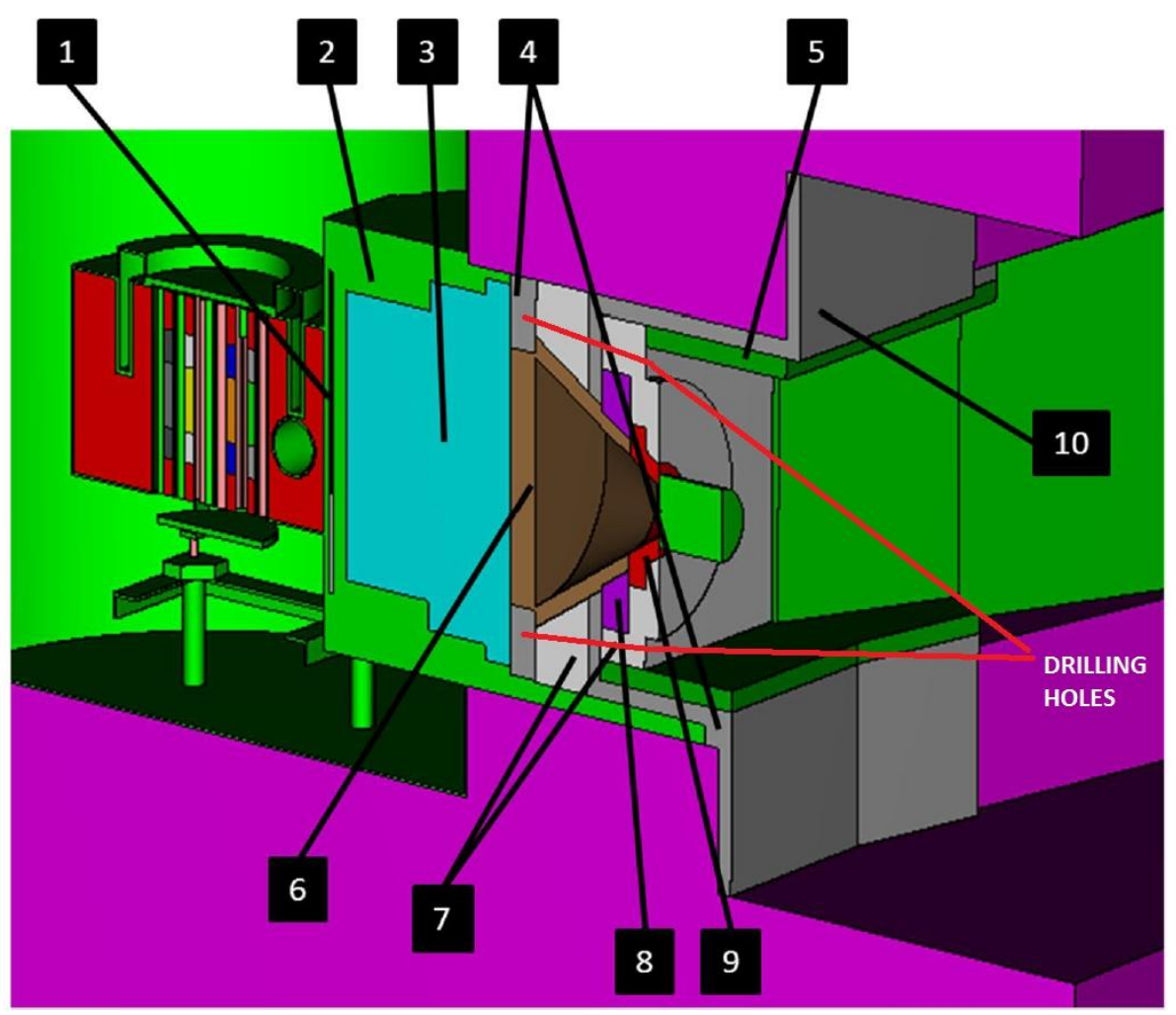

Figure 4: Location of the lead drilling holes marked with red color.

Table II: Components in Figure 4.

\section{Number in Figure 4. Component}

\begin{tabular}{|l|l|}
\hline $\mathbf{1}$ & Boral plate \\
\hline $\mathbf{2}$ & Aluminium \\
\hline $\mathbf{3}$ & Fluental moderator \\
\hline $\mathbf{4}$ & Lead shielding \\
\hline
\end{tabular}




\begin{tabular}{|l|l|}
\hline $\mathbf{5}$ & Lithium carbonate plastic shielding \\
\hline $\mathbf{6}$ & Bismuth plate and cone \\
\hline $\mathbf{7}$ & Li-Nat RX215 plastic shielding \\
\hline $\mathbf{8}$ & Li 3.5\% enriched RX215 plastic shielding \\
\hline $\mathbf{9}$ & Li 7\% enriched plastic collimator \\
\hline $\mathbf{1 0}$ & Steel encapsulation for lead shielding \\
\hline
\end{tabular}

The impurities of the drilled lead samples were measured with High Resolution sector field Inductively Coupled Plasma Mass Spectrometer (HR ICP-MS, Element 2, ThermoScientific). Lead samples, with mass less than $200 \mathrm{mg}$ were purified in $1 \mathrm{M} \mathrm{HNO}_{3}$ and ethanol ( $\left.\geq 99.5 \%\right)$ prior to the microwave assisted acid digestion. Samples were weighted before and after the purification and 6.2 - $9.6 \mathrm{mg}$ mass loss was detected due to the purification of the samples. Samples were completely dissolved in $\mathrm{HNO}_{3}$ and milliQ water (Millipore) solution ( $3 \mathrm{~mL}$ concentrated $\mathrm{HNO}_{3}+3 \mathrm{~mL}$ milliQ water) with microwave digestion unit (Milestone MLS $1200 \mathrm{Mega}$ ). Digested samples were diluted to $50 \mathrm{~g}$ with milliQ water. Further, for HR ICP-MS analysis samples were diluted 1/5, 1/10, 1/100 and $1 / 100000$ with $1 \%$ nitric acid solution. $10 \mu \mathrm{g} / \mathrm{L}$ of rhodium was added as internal standard to all samples.

Calibration curve and control samples were diluted from ICP-MS Multi-Element Solutions 2 and 4 (SPEX), and control samples from Semi-Quantitative Standard (SQS-1, AccuTraceTM ) and Laboratory Performance Check Standard 1 (LPC-1, SPEX) solutions. $10 \mu \mathrm{g} / \mathrm{L}$ of Rh was used as an internal standard in all samples, background, calibration and control samples. The samples were injected through SeaSpray nebulizer $(0.4 \mathrm{ml} / \mathrm{min})$ and double pass spray chamber equipped with Peltier cooling unit. Aluminum sample cone and Nickel skimmer cone were used during the measurement. Final results and measurement relative standard deviations (RSD) are listed in Table III.

Table III: Measured impurities and relative standard deviations (RSD) of lead in the BNCT station.

\begin{tabular}{|c|c|c|c|c|c|c|c|c|}
\hline Nuclide & $w \%$ & $\begin{array}{l}\text { RSD } \\
(\%)\end{array}$ & Nuclide & ppm & $\begin{array}{l}\text { RSD } \\
(\%)\end{array}$ & Nuclide & ppm & $\begin{array}{l}\text { RSD } \\
(\%)\end{array}$ \\
\hline Ag-107 & 2.59E-04 & 4.40 & $\mathrm{Fe}-56$ & $1.41 \mathrm{E}-04$ & 5.40 & Sb-121 & 9.31E-05 & 3.53 \\
\hline Cd-111 & 8.46E-07 & 24.00 & $\mathrm{Ni}-60$ & 1.20E-05 & 8.88 & Cr-52 & 7.60E-07 & 15.88 \\
\hline Sn-118 & 1.64E-06 & 16.95 & Cu-63 & 2.98E-04 & 5.33 & Co-59 & 1.22E-07 & 34.75 \\
\hline $\mathrm{Bi}-209$ & 1.23E-03 & 5.58 & Zn-66 & 4.23E-05 & 8.83 & & & \\
\hline Ca-44 & $1.51 \mathrm{E}-03$ & 4.80 & As-75 & 9.46E-06 & 4.23 & & & \\
\hline
\end{tabular}




\begin{tabular}{|l|l|l|l|l|l|}
\hline Mn-55 & $1.57 \mathrm{E}-07$ & 15.00 & Se-77 & $2.31 \mathrm{E}-05$ & 14.00 \\
\hline
\end{tabular}

Lead samples were measured at the end February 2017 using Canberra's ISOCS gammaspectrometer [12] with HPGe detector (BE2020), Inspector 2000 DSP analyzator and Genie 2000 v.3.4 gamma analysis software. The efficiency calibration were done with Geometry Composer-program (version 4.4). For gamma measurements the drilled lead samples (first corkscrew-like samples) were rotated to spiral-like discs to ease the efficiency calibration done with Geometry Composer-program. Measurement time was around 24 hours.

Results are listed in Table IV. Listed values are averages from four measured parallel samples.

Table IV: Comparison of measured and calculated gamma activities. Estimated uncertainties are given in parentheses.

\begin{tabular}{|l|l|}
\hline $\begin{array}{l}\text { Sample / specific } \\
\text { activity }\end{array}$ & $\mathbf{A g}-\mathbf{1 1 0 M}(\mathbf{B q} / \mathbf{g})$ \\
\hline Average measured & $0.81(0.07)$ \\
\hline Average calculated & $0.93(0.09)$ \\
\hline
\end{tabular}

Apart from silver-110M measured activities were smaller than minimum detectable activities. In addition, after a decay time of around 600 days some Ag-108M, Fe-55, Ni-63 and Zn-65 activities could be expected, but based on activation calculation, all these values are clearly below Finnish clearance levels. Consequently, lead in the BNCT station can very likely be cleared from regulatory control.

\section{III.B. ALUMINUM}

FiR1 reactor contains aluminum in the reactor tank, horizontal beam tubes and in most of the equipment inside the tank. Aluminum parts are illustrated in Figure 5. 


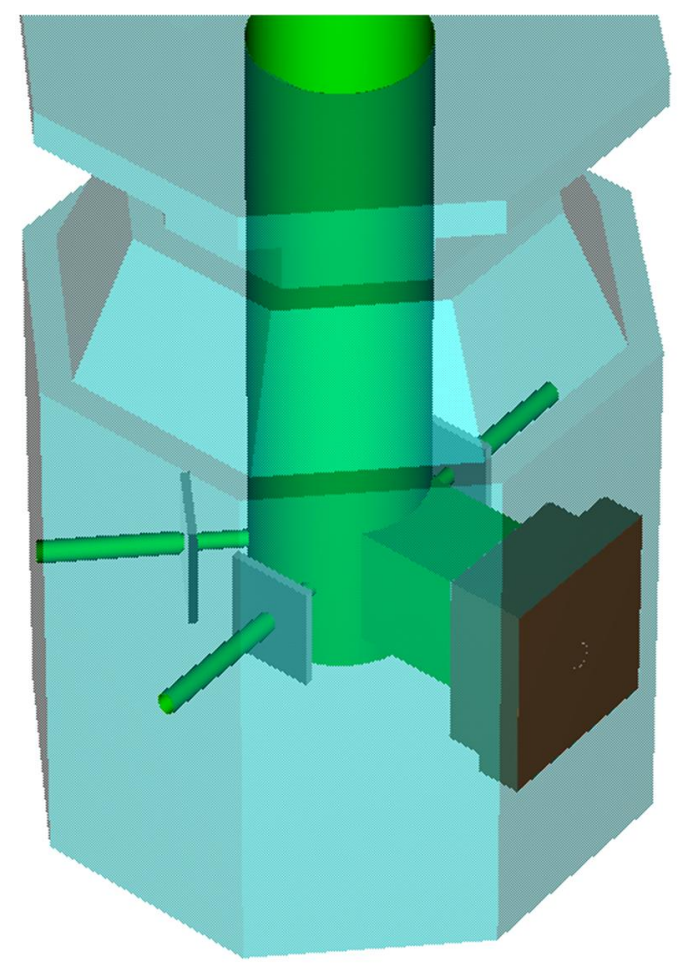

Figure 5: Aluminum parts in FiR1 reactor are illustrated in green color.

Only small impurities of e.g. cobalt, iron, nickel and zinc activate in aluminum. Specific activities are much lower than in steel parts, but all the aluminum structures near the core region are still active and need to be considered as low- and intermediate level nuclear waste. Nevertheless, typical power reactors seldom contain any aluminum parts and consequently the safety of final disposal of aluminum has not been studied as thoroughly. Chemical behavior of FiR1 aluminum in active waste final disposal conditions has been studied at VTT in Reference [14].

Aluminum was sampled from the inactive upper parts of the tank. According to the manufacturing specification, the aluminum should be of AlMg3 type. The tank, thermal column walls and beam tubes were manufactured in Finland by Alstrom company, whereas smaller special components (grid plates, tubes, etc.) were manufactured in US by General Atomics.

The approach was to measure the composition with inactive samples and irradiate a few of those to validate the computational activation mechanisms. 
The composition of aluminum was measured with HR ICP-MS technique from three samples from the upper parts of the reactor tank. . Aluminum samples, with mass less than $300 \mathrm{mg}$ were purified in $1 \mathrm{M} \mathrm{HNO3}$ and ethanol ( $\geq 99.5 \%$ ) prior to the microwave assisted acid digestion. Samples were completely dissolved in aqua regia $(5 \mathrm{~mL})$ with microwave digestion unit. Digested samples were diluted to $100 \mathrm{~g}$ with milli-Q water. Further, for HR ICP-MS analysis samples were diluted 1/2, 1/10, $1 / 100$ and $1 / 10000.10 \mu \mathrm{g} / \mathrm{L}$ of indium was added as internal standard to all samples.

Calibration curve and control samples were diluted from ICP-MS Multi-Element Solutions 2 and 4 (SPEX), and control samples from Semi-Quantitative Standard (SQS-1, AccuTraceTM ) and Laboratory Performance Check Standard 1 (LPC-1, SPEX) solutions. $10 \mu \mathrm{g} / \mathrm{L}$ of In was used as an internal standard in all samples, background, calibration and control samples.

The samples were injected through SeaSpray nebulizer $(0.4 \mathrm{ml} / \mathrm{min})$ and double pass spray chamber equipped with Peltier cooling unit. Aluminum sample cone and nickel skimmer cone were used during the measurement. Results including measurements relative standard deviations (RSD) are presented in Table V. Results are average values from three parallel samples.

Table V: Measured aluminum composition [ppb] and measurement relative standard deviations (RSD).

\begin{tabular}{|c|c|c|c|c|c|c|c|c|}
\hline Material & ppb & RSD (\%) & Material & ppb & RSD (\%) & Material & ppb & RSD (\%) \\
\hline Li-7 & 228 & 24 & Pb-208 & 24025 & 1 & Cr-52 & 2006694 & 1 \\
\hline B-11 & 2092 & 7 & Bi-209 & 70 & 2 & Mn-55 & 784529 & 1 \\
\hline Sr-88 & 44 & 10 & Th-232 & 116 & 2 & Fe-56 & 3805567 & 1 \\
\hline Zr-90 & 6308 & 1 & U-238 & 1195 & 2 & Co-59 & 900 & 3 \\
\hline Mo-95 & 3216 & 1 & Na-23 & 1338 & 9 & Ni-60 & 17184 & 1 \\
\hline Ag-107 & 188 & 1 & Mg-24 & 11397907 & 1 & Cu-63 & 1830652 & 1 \\
\hline Cd-111 & 555 & 1 & Al-27 & 974157202 & 1 & $\mathrm{Zn}-66$ & 308425 & 2 \\
\hline Sn-118 & 8934 & 1 & Si-28 & 4251635 & 12 & Ga-69 & 84170 & 1 \\
\hline Cs-133 & 8 & 140 & P-31 & 1206 & 6 & K-39 & 276 & 2 \\
\hline Ba-137 & 415 & 5 & S-32 & 1846 & 18 & Ge-72 & 327 & 1 \\
\hline Ta-181 & 1 & 5 & Ca-44 & 2313 & 4 & As-75 & 94 & 17 \\
\hline W-182 & 1242 & 1 & Sc-45 & 104 & 1 & Se-77 & 536 & 235 \\
\hline Re-185 & 0 & 108 & Ti-47 & 143215 & 2 & Se-78 & 1122368 & 14 \\
\hline TI-205 & 274 & 1 & V-51 & 32603 & 1 & & & \\
\hline
\end{tabular}


Samples of inactive aluminum from the upper parts of the reactor tank were irradiated in FiR1 reactor before shutdown in June 2015. Samples were irradiated in the irradiation ring around the core in a neutron flux of $2.32 \times 10^{12} \mathrm{n} / \mathrm{s} \times \mathrm{cm}^{2}$ and cadmium ratio of 2.02 . Two of the samples were irradiated for four hours and one of them was irradiated for 14 hours.

Two of these activated samples were studied with ISOCS gammaspectrometry system [12] [15]. Used detector was BE2020 and the calibrations were done using ISOCS version 4.3. Small samples were measured as close as possible, top of the detector. Specific activities were also calculated with the same method as in [7] using the measured aluminum composition. The calculation contains still some uncertainties due to neglecting the shielding effect of the irradiation capsule and neutron input spectrum cannot be modelled exactly. An estimate for the calculation uncertainly is around ten percent. The results show that at the time of measurements, a specific activity of around $2.7 \mathrm{kBq} / \mathrm{g}$ is expected. Main contributing nuclides will be Cr-51, Fe-55, Zn-65, Mn-54, Fe-59, Ni59, Ni-63, Sc46 and Co-60. Measured spectrum is illustrated in Figure 6. Uncertainties in the measurement arise mainly from separating the background from the measurement data and converting the $\mathrm{cpm}$ to $\mathrm{Bq} / \mathrm{g}$. Moreover, the material composition of the samples has been assumed to be homogenous, but in real life some variations always occur. Comparison between the measured and calculated gamma activities is presented in Table VI. 


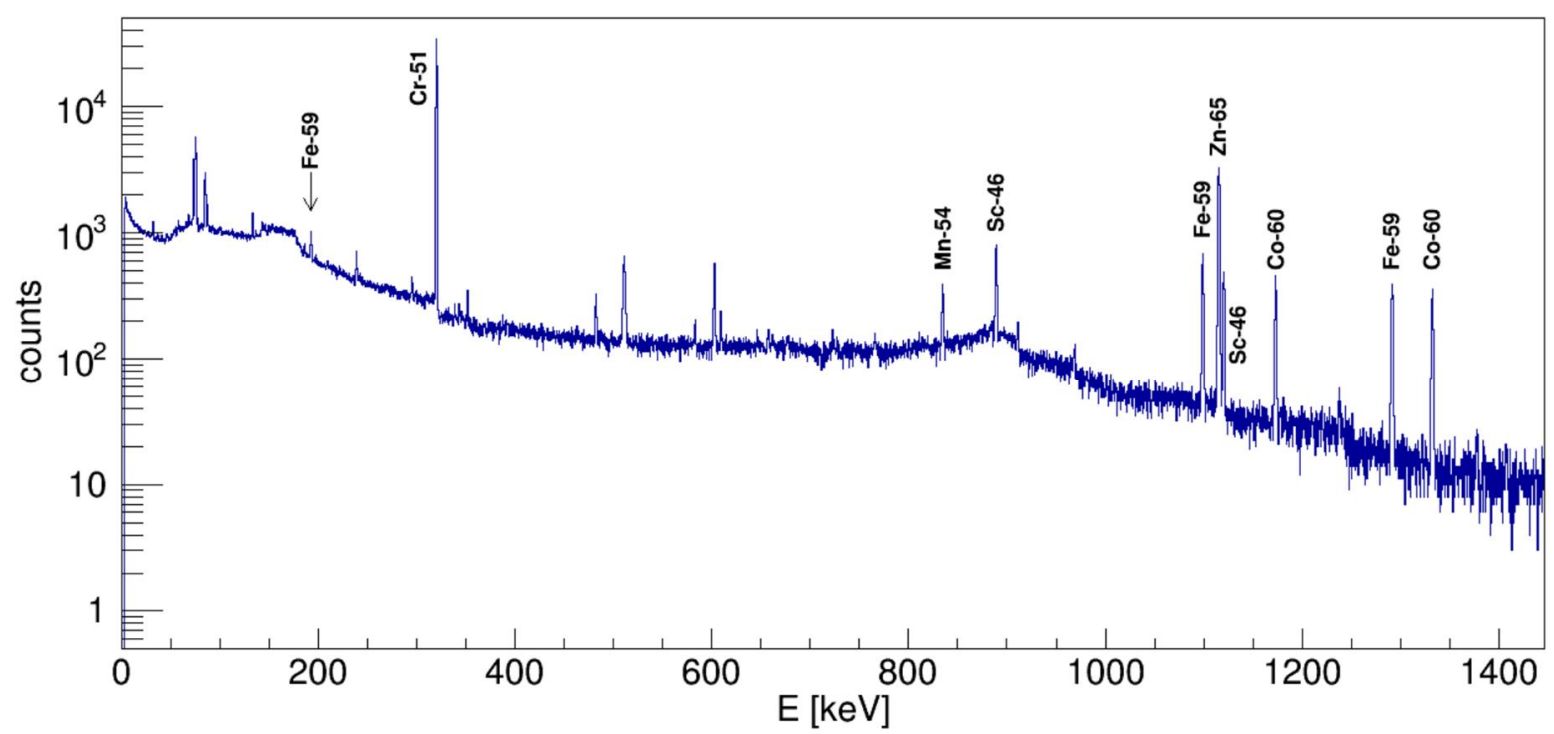

Figure 6: Measured gamma spectrum for aluminum.

Table VI: Specific activities of the studied samples.

\begin{tabular}{|l|l|l|l|l|l|}
\hline Nuclide & $\begin{array}{l}\text { Half- } \\
\text { life } \\
\text { (days) }\end{array}$ & $\begin{array}{l}\text { Measured } \\
\text { activity } \\
\text { (Bq/g) }\end{array}$ & $\begin{array}{l}\text { Measurement } \\
\text { uncertainty } \\
\text { (\%) }\end{array}$ & $\begin{array}{l}\text { Calculated } \\
\text { activity } \\
\text { (Bq/g) }\end{array}$ & $\begin{array}{l}\text { Calculation } \\
\text { uncertainty } \\
\text { (\%) }\end{array}$ \\
\hline Sc-46 & 83.79 & 5.46 & 2.9 & 7.4 & 10 \\
\hline Cr-51 & 27.7 & 699 & 4.7 & 639 & 10 \\
\hline Mn-54 & 312.2 & 1.80 & 7.9 & 4.1 & 10 \\
\hline Fe-59 & 44.5 & 13.5 & 2.9 & 20.7 & 10 \\
\hline Co-60 & 1925 & 5.24 & 3.0 & 18.4 & 10 \\
\hline Zn-65 & 243.9 & 81.1 & 3.0 & 133.9 & 10 \\
\hline
\end{tabular}

Specific activities correspond to the values reasonably well and provide a basis for further aluminum waste characterization and classification. Apart from short living $\mathrm{Cr}-51$, assumptions in the calculated values also result in a conservative estimate. However, Cr-51 is short living nuclide with a half life of only 27.7 days. Considering the half-lives and nuclide-wise clearance levels, Co-60 will be chosen as a key nuclide for aluminum in future waste measurements.

\section{III.C. GRAPHITEMFASUREMENIS}

FiR1 research reactor contains graphite both in the reflector around the core and in $1.2 \times 1.2 \times 1.74 \mathrm{~m}$ thermal column that was disassembled in 1995. Disassembled graphite is stored at VTT premises in Finland. 


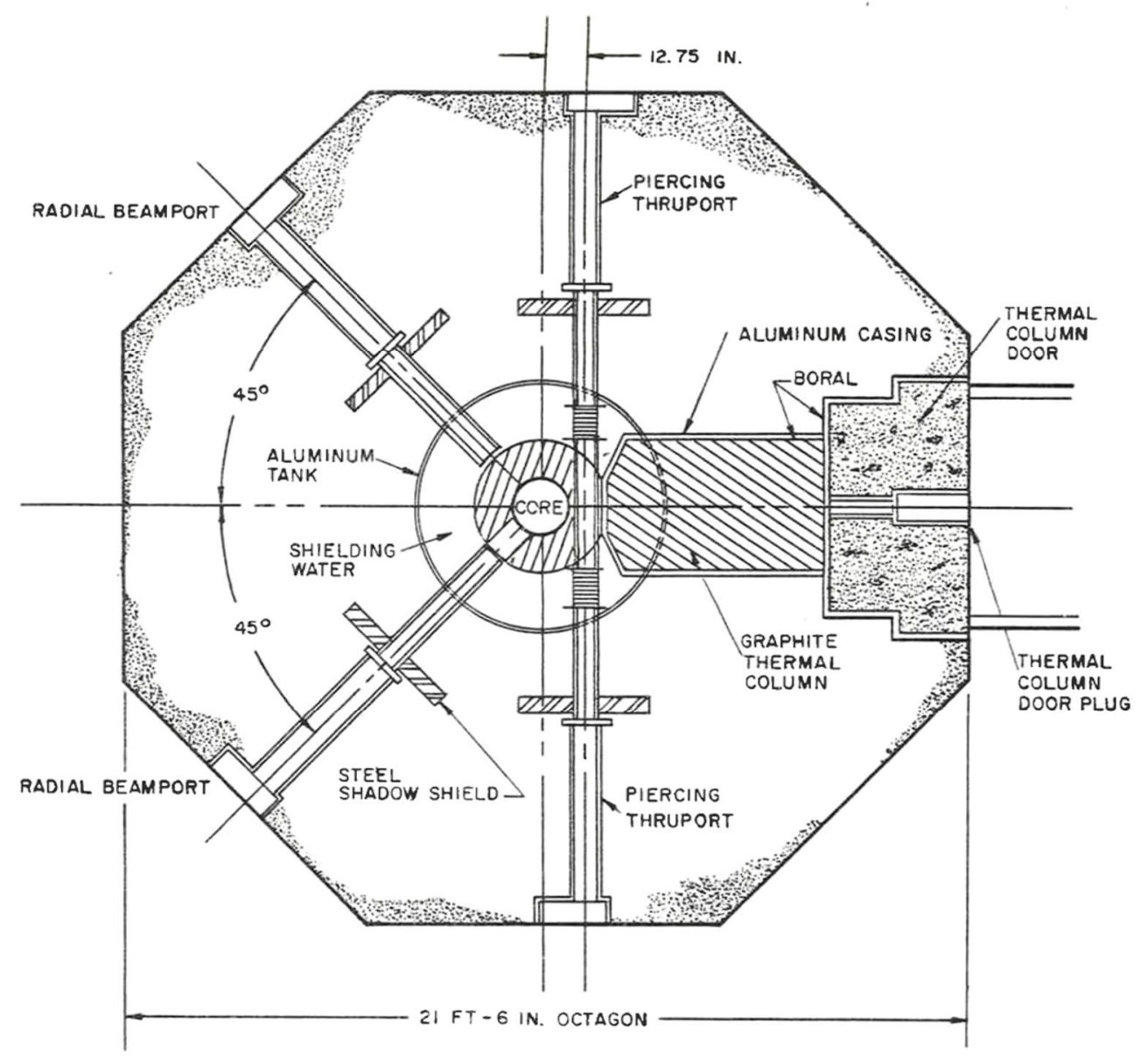

Figure 7: Graphite in FiR1 reactor is illustrated on the right side of the core [7].

Graphite is a porous material, and the most important activation mechanism in the material is the activation of nitrogen in the air of the porous holes into carbon-14 via reaction $N-14(n, p) C-14$. Carbon-14 is an especially important nuclide in waste disposal, because it spreads rapidly in the biosphere. Other important isotopes are e.g. Eu-152, Eu-154 and Co-60. Moreover, power reactors in Finland do not contain any active graphite, and thus it has not been studied as thoroughly. The chemical behavior of active graphite in final disposal conditions has also been studied at VTT in a separate report [14]. 
In this study, carbon-14 activity of cylindrical $1.0 \times 1.0 \mathrm{~cm}$ samples from thermal column graphite have been measured both at VTT and at the University of Helsinki radioisotope laboratory in Viikki, Finland.

Nuclides that emit only low energy beta radiation, such as tritium and carbon-14, are hard to measure from graphite with normal liquid scintillation counting, because of the poor solubility of the material in scintillation liquid. However, these problems are not present if the sample is oxidized to volatile oxides measuring the activity from their oxides is much easier. VTT measured the graphite samples with Junitek Oxidizer (Junitek co, Finland) device at the University of Helsinki isotope laboratory in Viikki, Finland. Samples of $100 \mathrm{mg}$ were studied. Junitek Oxidizer is based on dry oxidation method and uses pure oxygen to fully burn the sample to water and carbon dioxide at a temperature of $960^{\circ} \mathrm{C}$. CO2 reacts with the amine in the reaction column to form carbamate. The released gases are cooled. Water and air rinsing through the reaction column and collect carbon-14 to liquid scintillation counter bottle. The operating principle is illustrated in Figure 8 and final results with estimates of measurement errors are listed in Table VII. Measurement errors arise partially from collecting the gasses and from performing the LSC measurement.

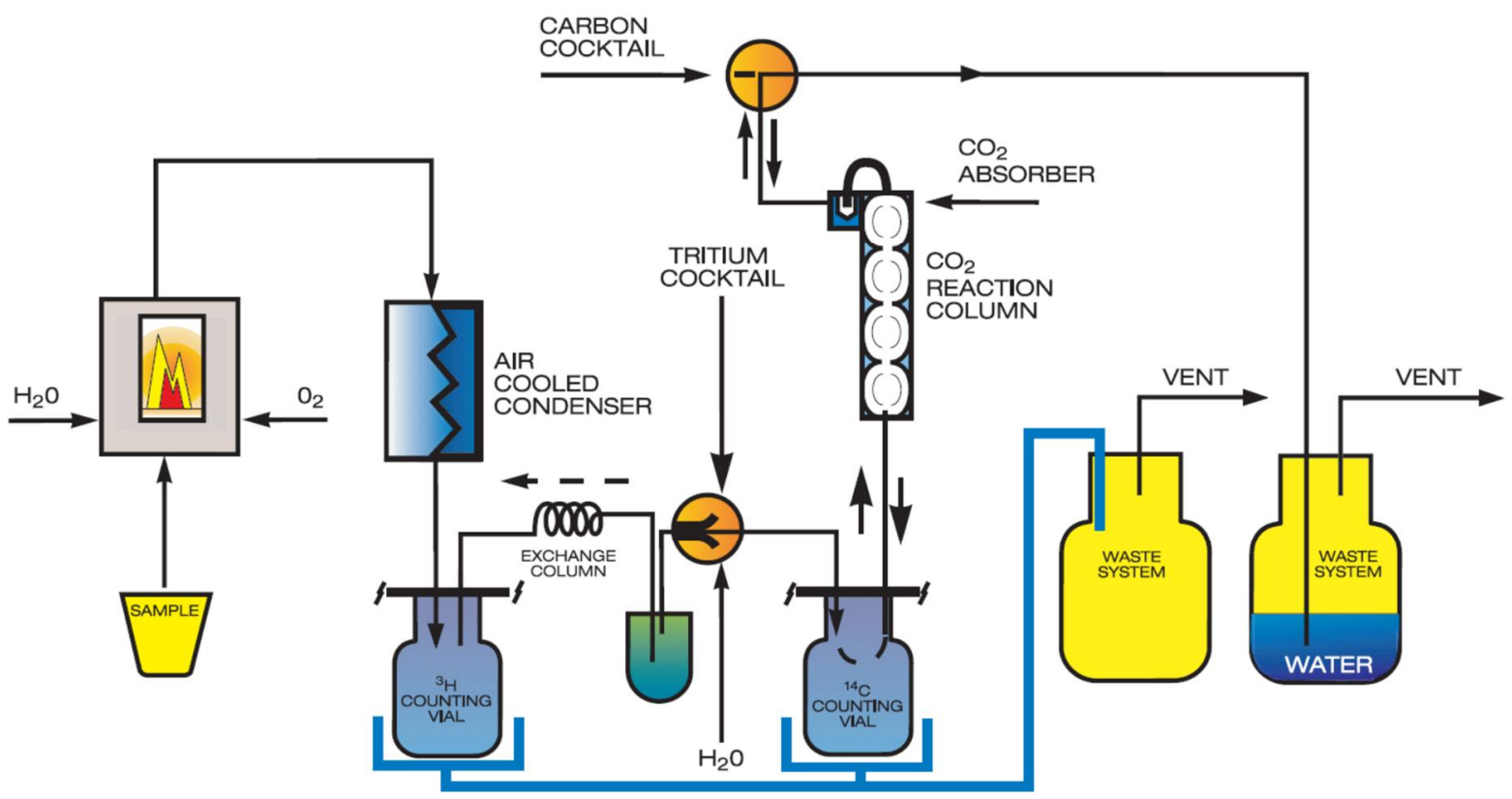

Figure 8: Operating principle of oxidizer device. 
Table VII: Measured carbon-14 activities from samples 1-8.

\begin{tabular}{|c|c|c|c|c|c|c|c|c|c|}
\hline Sample & 1 & 2 & 3 & 4 & 5 & 6 & 7 & 8 & $\begin{array}{l}\text { Average } \\
(\mathrm{kBq} / \mathrm{g})\end{array}$ \\
\hline $\mathrm{kBq} / \mathrm{g}$ & 0.293 & 0.115 & 0.001 & 0.023 & 1.660 & 0.241 & 0.100 & 0.393 & 0.353 \\
\hline $\begin{array}{l}\text { Estimated } \\
\text { measurement } \\
\text { error }(\%)\end{array}$ & 4.9 & 5.1 & 23.6 & 6.6 & 4.5 & 4.8 & 5.2 & 4.7 & \\
\hline
\end{tabular}

Activities in the thermal column graphite have been calculated earlier [7]. Calculated activity profile of $\mathrm{C}-14$ in the graphite is presented in Figure 9.

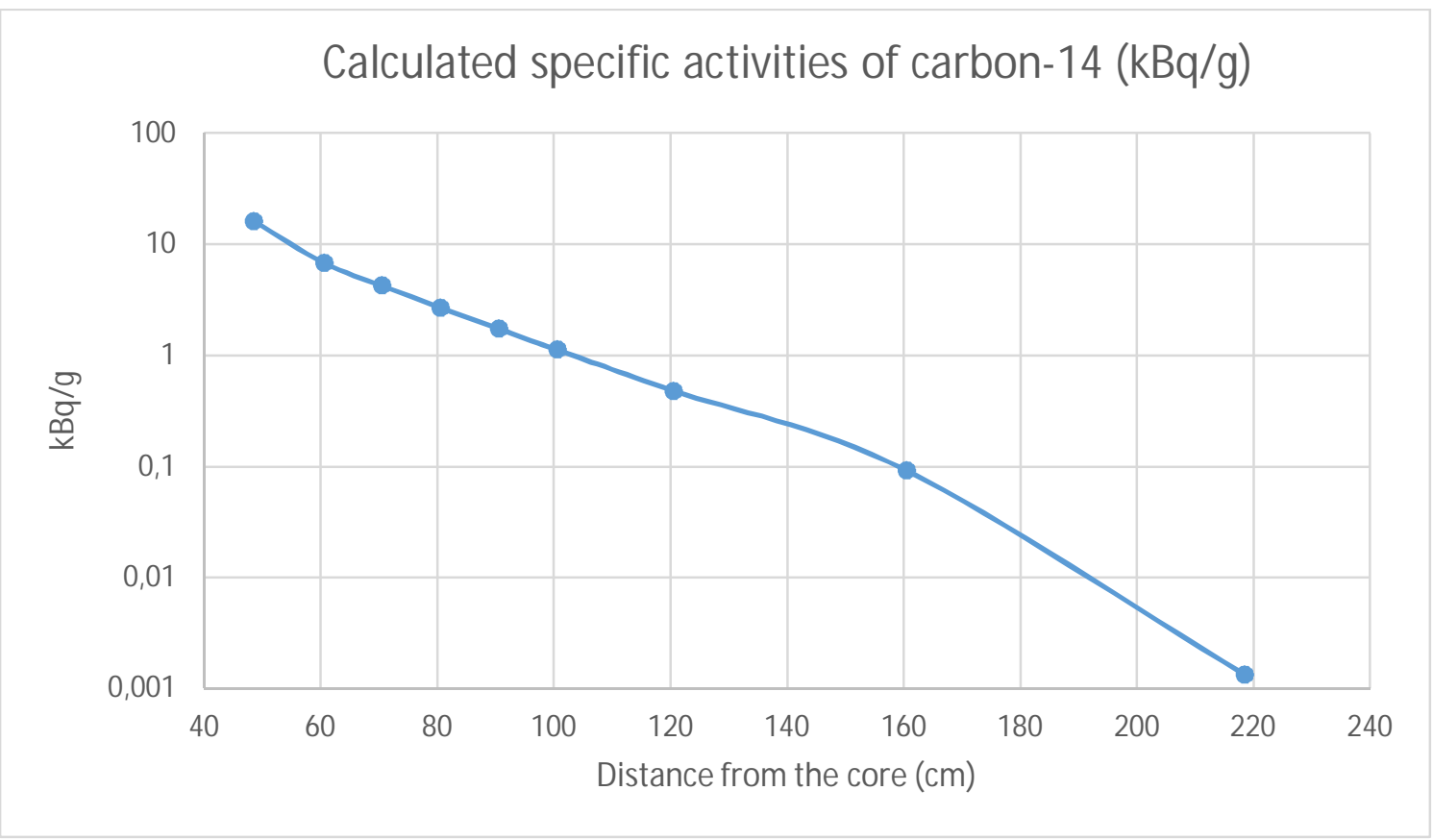

Figure 9: Calculated specific activities of $\mathrm{C}-14$ in thermal column graphite as the function of distance from the core.

Unfortunately exact location of samples in the old thermal column was not saved, but based on dose rate measurements, samples were collected from graphite blocks around the middle of the thermal column. Comparing the measured and calculated specific activities, a reasonable correspondence is seen. However, other radionuclide from same graphite samples need to be studied in the future. This includes especially chemical dissolving and measuring exact chlorine and europium fractions. 


\section{III.D. LTHIIUMENRICHEDPLASTICS}

FiR1 contains lithium enriched plastic that has been used as a neutron shielding material in the BNCT irradiation room. It is a mixture of lithium carbonate $\left(\mathrm{Li}_{2} \mathrm{CO}_{3}\right)$ and polyethylene paraffin. Shielding plastics is estimated to contain some tritium due to thermal neutron absorption of Li-6. No other significant activities are expected. Nevertheless, a large part of the tritium may have released from the porous material, and total activities may be close to clearance limits. Plastic samples were studied by full combustion method at Horia Hulubei National Institute for Physics and Nuclear Engineering (IFIN-HH).

The latest inventory calculations model [7] of the decommissioning waste does not contain a detailed model of neutron spectrum inside the BNCT irradiation room, but earlier estimates indicate that fluxes can be at highest around $10^{6}$ neutrons $/ \mathrm{sec} \times \mathrm{cm}^{2}$. However, it is expected that the fluxes can vary a lot inside the room. With the assumed neutron flux, computational estimates show that specific tritium activities in the shielding plastic can be at highest around a few hundred $\mathrm{Bq} / \mathrm{g}$.

Studied samples were drilled from six locations around the room as illustrated in Figure 10. Points 3 and 4 are from two adjacent plastic plates on top of each other. Sample number 3 was the innermost one. Two parallel samples of all location were prepared. 


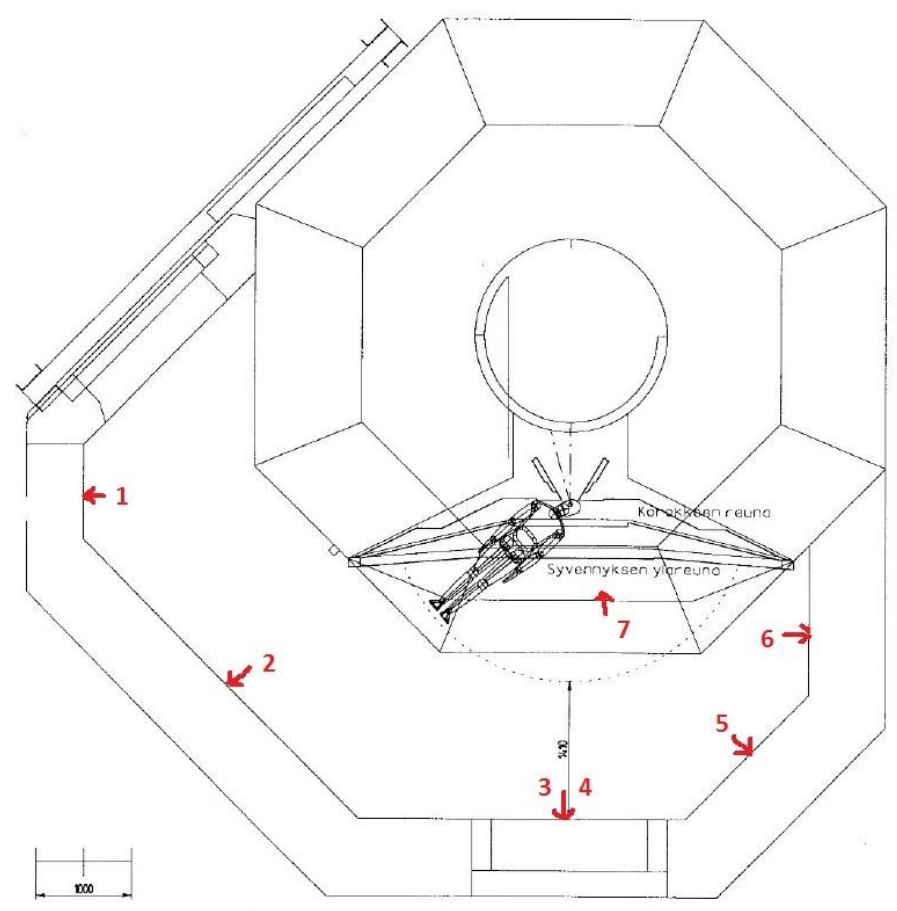

Figure 10: Locations of drilling holes.

Parallel samples of drilled lithium-enriched plastics were sent to IFIN-HH institute to be studied with full combustion oxidation method. The measurement system consisted of a pressurised oxygen tube and two heated tube furnaces that were used for sample oxidation and catalytic oxidation of produced gases at temperature of around $750^{\circ} \mathrm{C}$. Gases were collected to water, which was then measured with liquid scintillation counting method. The measurement setup is illustrated in Figure 11. 


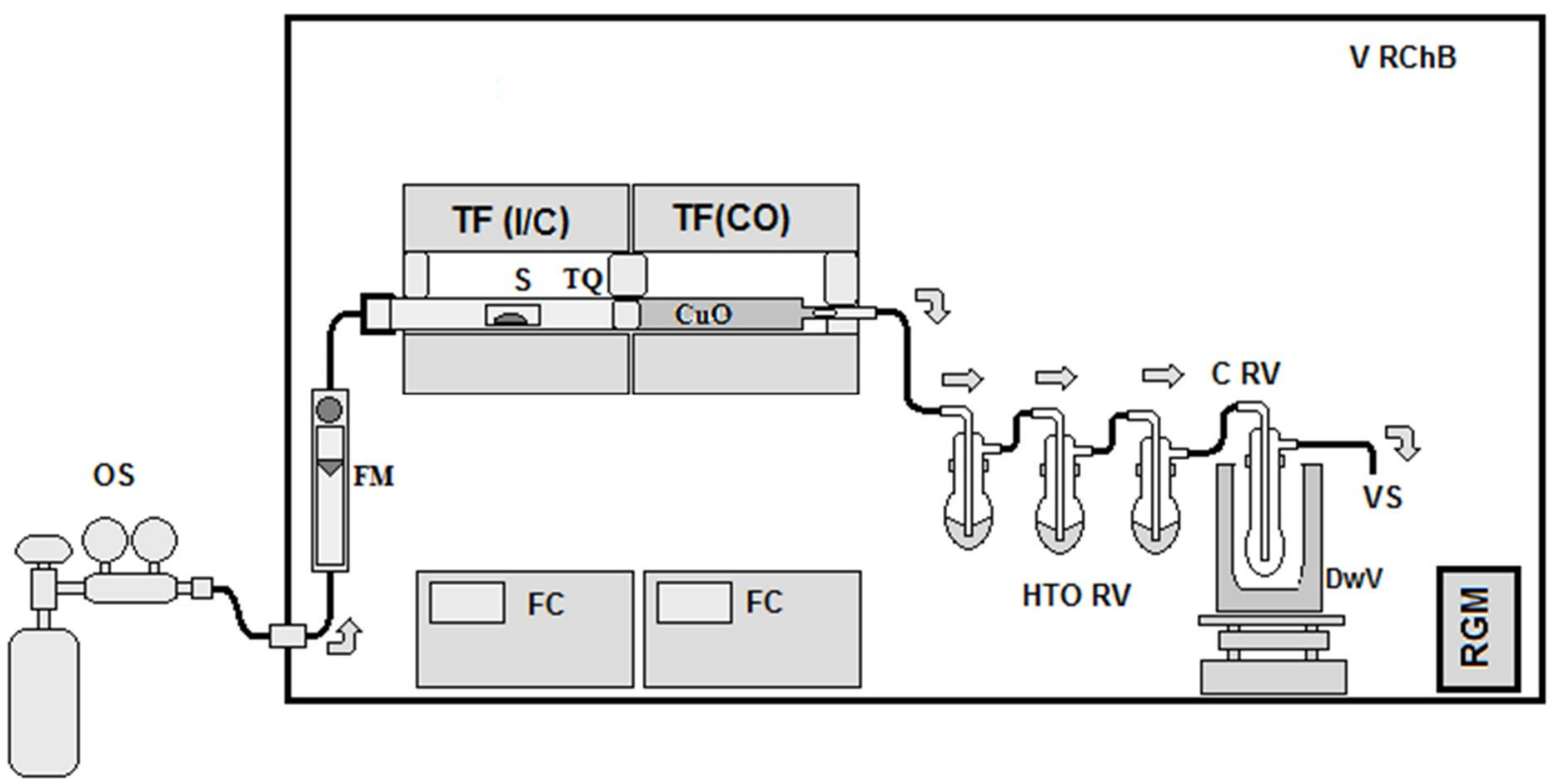

Figure 11: Schematic view of the oxidizer with retention of resulted HTO. QS- Oxygen supply; FMFlow-meter; TF (I/C)- Tube furnace (Incineration/Calcination); FC- Furnace controllers: TF (CO)Tube Furnace (Catalytic Oxidation); TQ- Quartz tube; S- Sample; CuO - CuO wire oxidation bed; HTO RV - HTO Collector with 3 retention vials; C RV- Cryogenic retention vial, DwV -Dewar vessel RGM- Radioactive gas monitor, V RChB - ventilated Radiochemical Box 
Studied drill cores were cut into disks and smaller pieces to be able to study the inner portions of the material, since the assumption was that tritium may have diffused from the outer parts of the samples. Eventually only the three inner cubic pieces were measured. The cutting protocol is presented in Figure 12.

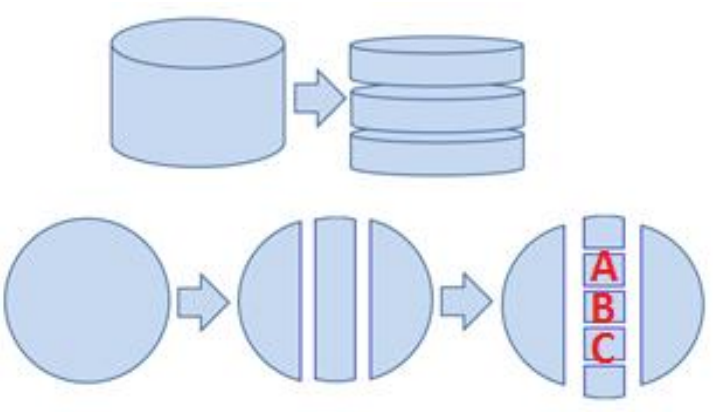

Figure 12: Cutting of the drill cores.

Samples were oxidized by gradually increasing the temperature to $750^{\circ} \mathrm{C}$ in around 120 minutes (see Figure 13) with oxygen flow rate of 4 liters/min.

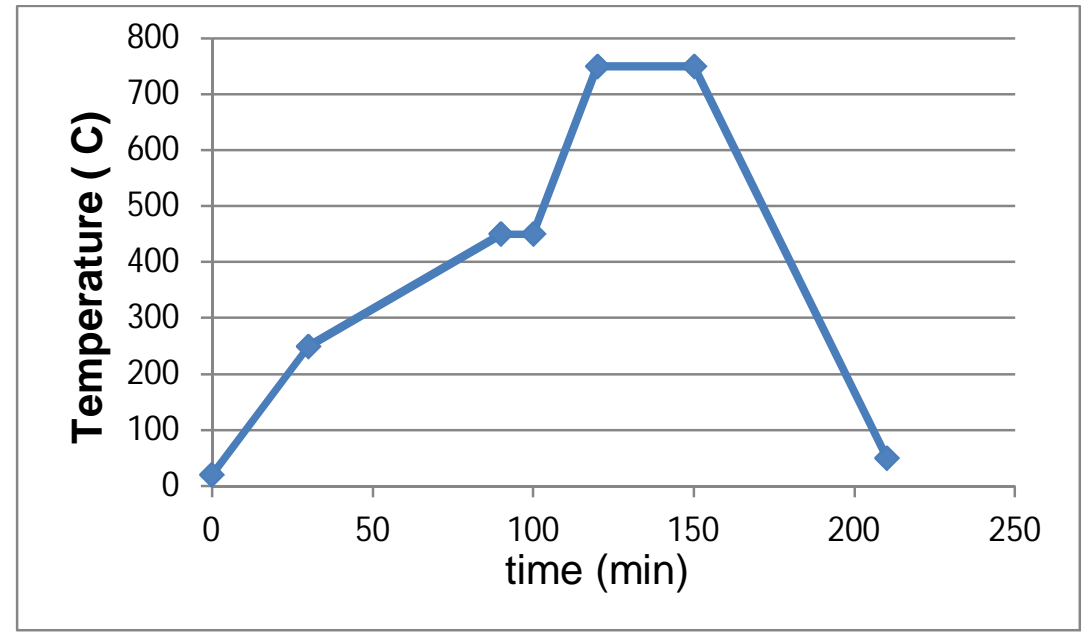

Figure 13: Temperature/time diagram applied for polyethylene $/ \mathrm{Li}_{2} \mathrm{CO}_{3}$ composite oxidation

$15 \mathrm{ml}$ of tritiated water was collected from three retention vials to be measured in with liquid scintillation counting technique. 
Specific activities were obtained by incineration of samples, tritiated water retaining and determination of the activities at Liquid Scintillation Counter. Obtained specific activities are listed in Table VIII.

Table VIII: Measured H-3 specific activities. Sample numbers refer to drilling locations in Figure 10.

\begin{tabular}{|c|c|c|c|c|c|}
\hline Sample & $\begin{array}{l}\text { Activity determined } \\
\text { with LSC (Bq) }\end{array}$ & $\begin{array}{l}\text { Activity- } \\
\text { Background }\end{array}$ & $\begin{array}{l}\text { Sample mass } \\
\text { (g) }\end{array}$ & df & As (Bq/g) \\
\hline $1 \mathrm{~A}$ & 6.658 & 6.0626 & 0.4977 & 15 & 190.618 \\
\hline 1B & 13.077 & 12.4818 & 0.5184 & 15 & 359.461 \\
\hline $1 \mathrm{C}$ & 2.105 & 1.5098 & 0.5084 & 15 & 58.996 \\
\hline \multicolumn{5}{|l|}{ Average } & 203.025 \\
\hline \multicolumn{5}{|c|}{ Standard deviation } & 150.616 \\
\hline $2 A$ & 25.714 & 25.1194 & 0.5089 & 15 & 720.044 \\
\hline 2B & 37.738 & 37.1426 & 0.5154 & 15 & 1043.385 \\
\hline 2C & 17.635 & 17.0402 & 0.5273 & 15 & 476.582 \\
\hline \multicolumn{5}{|l|}{ Average } & 746.670 \\
\hline \multicolumn{5}{|c|}{ Standard deviation } & 284.338 \\
\hline $3 A$ & 11.138 & 10.5434 & 0.5065 & 15 & 313.371 \\
\hline 3B & 21.758 & 21.1634 & 0.5179 & 15 & 598.682 \\
\hline $3 C$ & 9.726 & 9.1314 & 0.5219 & 15 & 265.570 \\
\hline \multicolumn{5}{|l|}{ Average } & 392.541 \\
\hline \multicolumn{5}{|c|}{ Standard deviation } & 180.116 \\
\hline 4A & 12.434 & 11.8386 & 0.5277 & 15 & 335.757 \\
\hline 4B & 17.147 & 16.5522 & 0.5180 & 15 & 471.714 \\
\hline 4C & 9.632 & 9.037 & 0.5141 & 15 & 266.983 \\
\hline \multicolumn{5}{|l|}{ Average } & 358.151 \\
\hline \multicolumn{5}{|c|}{ Standard deviation } & 104.186 \\
\hline $5 A$ & 17.890 & 17.2946 & 0.5170 & 15 & 519.041 \\
\hline 5B & 32.140 & 31.545 & 0.5160 & 15 & 934.302 \\
\hline $5 \mathrm{C}$ & 21.637 & 21.042 & 0.5170 & 15 & 627.766 \\
\hline \multicolumn{5}{|l|}{ Average } & 659.018 \\
\hline \multicolumn{5}{|c|}{ Standard deviation } & 204.573 \\
\hline $6 \mathrm{~A}$ & 10.079 & 9.4842 & 0.5181 & 15 & 277.222 \\
\hline 6B & 15.502 & 14.9074 & 0.5748 & 15 & 384.324 \\
\hline $6 \mathrm{C}$ & 13.090 & 12.4946 & 0.5238 & 15 & 356.103 \\
\hline \multicolumn{5}{|l|}{ Average } & 339.216 \\
\hline \multicolumn{5}{|c|}{ Standard deviation } & 55.512 \\
\hline $7 \mathrm{~A}$ & 31.849 & 31.254 & 0.5200 & 15 & 872.785 \\
\hline 7B & 32.637 & 32.042 & 0.5142 & 15 & 904.468 \\
\hline $7 C$ & 27.993 & 27.398 & 0.5068 & 15 & 787.096 \\
\hline \multicolumn{5}{|l|}{ Average } & 854.783 \\
\hline
\end{tabular}


Shielding plastics may have possibly re-use as shielding material in other institutes in Finland. Studied results indicate that their activity in relatively low and consequently from the point of radiation safety, there is no obstacle for re-use.

\section{III.E. CONARETE}

The aluminum tank in FiR1 reactor is surrounded by 1.5 meter thick layer of ordinary concrete, which serves as a biological shield. According to computational estimates in Reference [7], most of the concrete is inactive and activity is limited only close to the reactor core region about one meter from the surface of the tank and 0.5 meters around the beam tubes. Main radionuclides are Eu-152, Eu154, Co-60, Ca-45, H-3, Ni-63, Ni-59, and Fe-55. Neutron fluxes inducing the activity are illustrated in Figure 14.

Concrete has been studied at VTT by measuring its composition from three drill cores from the inactive outer part of the reactor and by measuring an active older drill core from the thermal column cavity.
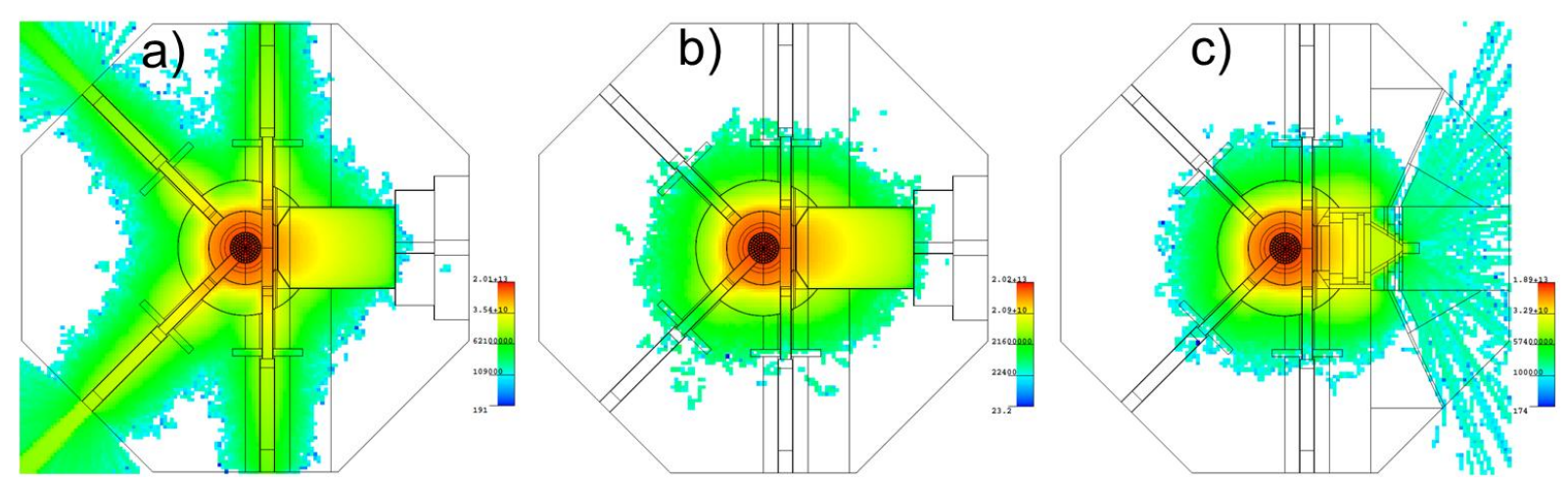

Figure 14: MCNP simulated total neutron fluence rates a) with thermal column and open beam ports, b) with thermal column and plugged beam ports, and c) with BNCT beam. [7]

Three drilling samples were taken from the outermost inactive part of the reactor to determine the detailed composition of the material. Direction of drilling is illustrated in Figure 15. 


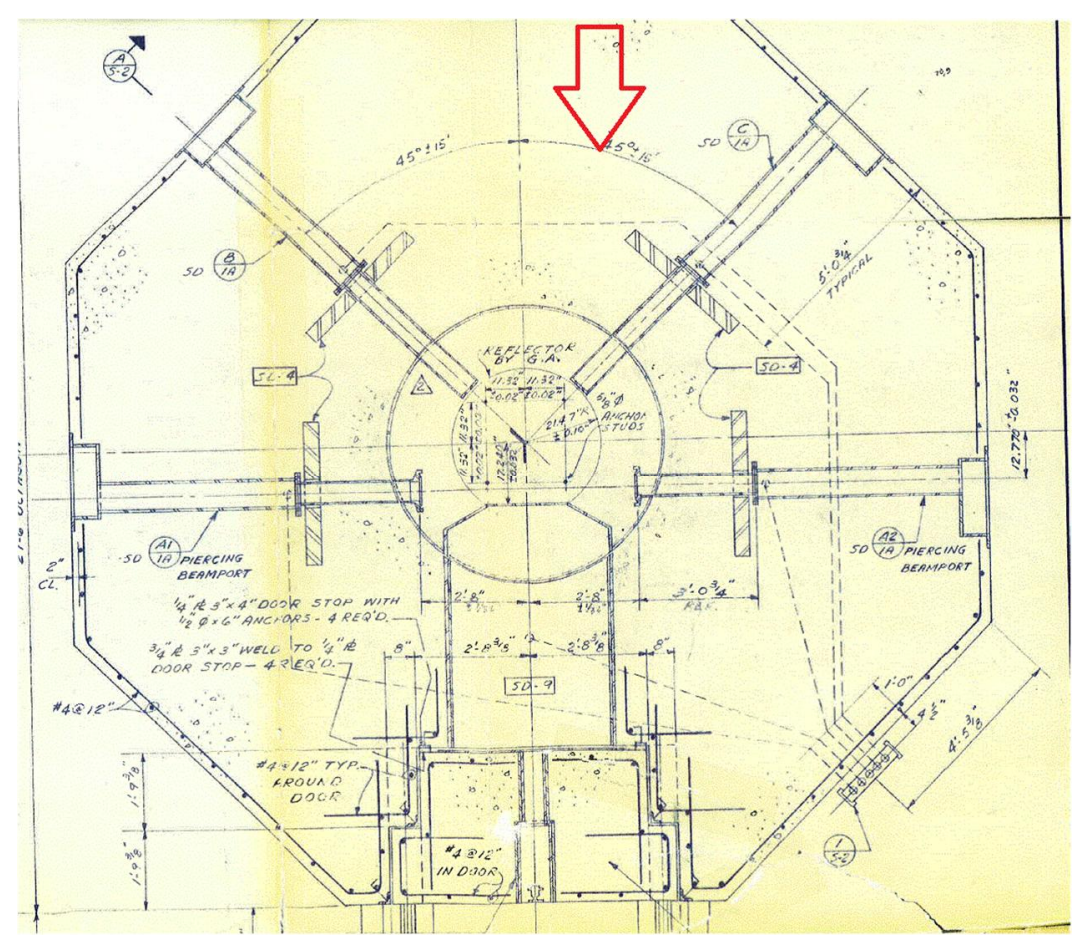

Figure 15: Direction of drilling.

Sample compositions were measured with inductively coupled optical emission spectrometry method by VTT Expert Services. Results are listed in Table IX. 
Table IX: Measured concrete composition.

\begin{tabular}{|c|c|c|c|c|}
\hline $\begin{array}{l}\text { Sample\# } \\
\text { element }\end{array}$ & / 1 (ppm) & 2 (ppm) & 3 (ppm) & $\begin{array}{l}\text { Measurement } \\
\text { uncertainties } \\
\text { (ppm) }\end{array}$ \\
\hline Al & 70300 & 67900 & 68050 & 100 \\
\hline B & 100 & 100 & 100 & 100 \\
\hline $\mathrm{Ba}$ & 860 & 890 & 840 & 20 \\
\hline C & 1730 & 1835 & 2165 & 80 \\
\hline $\mathrm{Ca}$ & 91000 & 79000 & 95000 & 100 \\
\hline $\mathrm{Cl}$ & 55 & 52 & 59 & 20 \\
\hline Co & 12 & 13 & 13 & 5 \\
\hline Cs & 1.9 & 1.7 & 1.7 & 100 \\
\hline Eu & 2.1 & 2.0 & 2.2 & 0.1 \\
\hline Fe & 23000 & 21000 & 23000 & 100 \\
\hline H & 4290 & 4150 & 4430 & 8 \\
\hline $\mathrm{K}$ & 35300 & 36450 & 33650 & 500 \\
\hline Li & 36 & 27 & 39 & 10 \\
\hline $\mathrm{Mg}$ & 9000 & 7700 & 8500 & 200 \\
\hline Mn & 350 & 310 & 370 & 10 \\
\hline $\mathbf{N}$ & 200 & 200 & 200 & 0.04 \\
\hline $\mathrm{Na}$ & 19000 & 20000 & 19000 & 100 \\
\hline $\mathrm{Ni}$ & 50 & 50 & 50 & 50 \\
\hline $\mathbf{P}$ & 500 & 500 & 500 & 500 \\
\hline $\mathbf{S}$ & 3200 & 2400 & 2900 & 200 \\
\hline Si & 258500 & 258500 & 258500 & 500 \\
\hline Sm & 8.3 & 8.0 & 13 & 0.1 \\
\hline $\mathrm{Ti}$ & 1380 & 1210 & 1370 & 100 \\
\hline $\mathbf{U}$ & 3.0 & 3.4 & 4.0 & 1 \\
\hline
\end{tabular}

Inventory calculations of concrete activity are based on conservative assumptions, namely choosing the maximum impurities of activating nuclides.

During the construction of the BNCT station in the 1990's parts of biological shield concrete were removed by diamond drilling. The drilling location is illustrated in Figure 16. The most active drill core was studied with gamma spectrometry. The computational specific activity for this sample was around $10 \mathrm{~Bq} / \mathrm{g}$. 


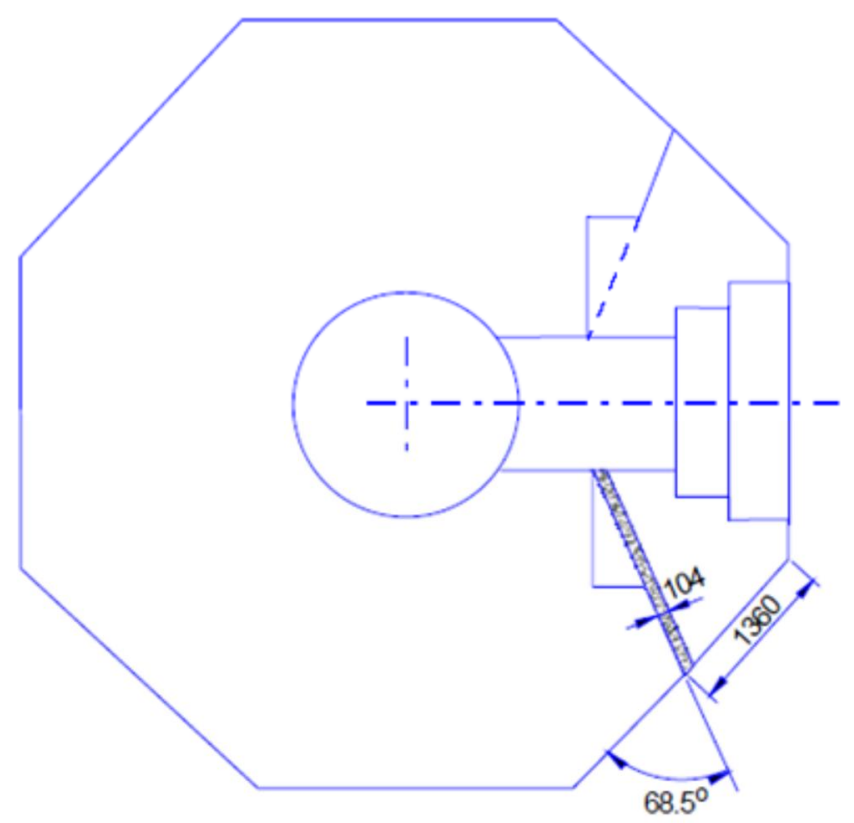

Figure 16: Original location of the drill core.

Gammaspectrometric measurements were performed using ISOCS system [15]. Used detector was BE2020 and the calibrations were done using ISOCS version 4.3. Distance from source to detector was $540 \mathrm{~mm}$. The measured spectrum is illustrated in Figure 17. Results and comparison with calculation are listed in Table $\mathrm{X}$.

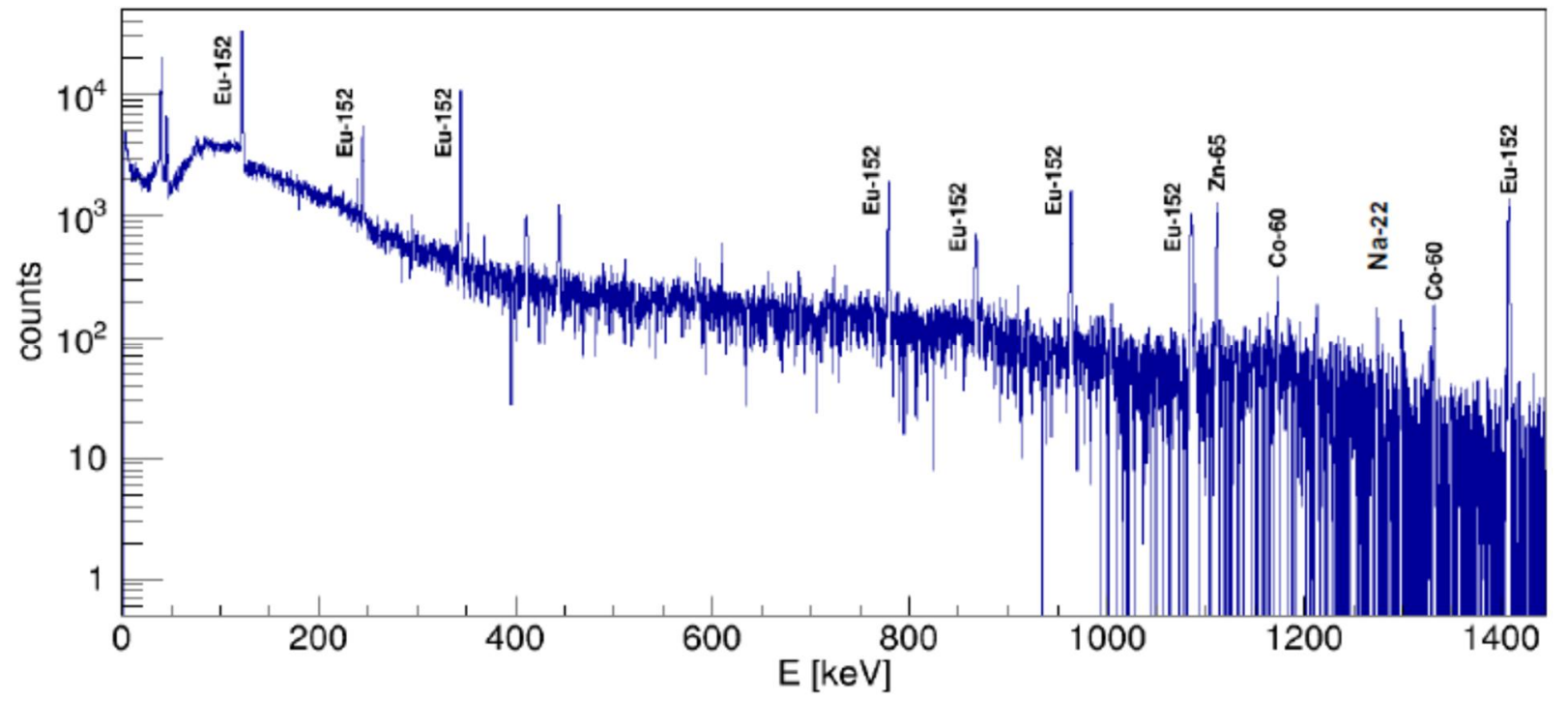

Figure 17: The gamma spectrum of the concrete sample. 
Table X: Comparison of measured and calculated gamma activities in concrete.

\begin{tabular}{|c|c|c|c|c|}
\hline Nuclide & Measured $(\mathrm{Bq} / \mathrm{g})$ & $\begin{array}{l}\text { Measurement } \\
\text { uncertainty }(\%)\end{array}$ & Calculated (Bq/g) & $\begin{array}{l}\text { Calculation } \\
\text { uncertainty (\%) }\end{array}$ \\
\hline Co-60 & $2.5 E-02$ & 6.93 & 2.6E-02 & 10 \\
\hline Eu-152 & $9.6 \mathrm{E}-01$ & 2.29 & 8.1E-01 & 10 \\
\hline
\end{tabular}

Uncertainties in the calculation arise from the facts input neutron spectrum cannot be modelled exactly. Moreover, the material composition of the samples has been assumed to be homogenous, but in real life some variations always occur. However, a separate calculation was performed for this exact location and measured concrete composition was used as input quantity. An uncertainty of ten percent was estimated. Measurement uncertainties arise mainly from separating the background from the measurement data and converting the $\mathrm{cpm}$ to $\mathrm{Bq} / \mathrm{g}$. Bearing these in mind, specific activities correspond to the values reasonably well, although the measured sample was quite old and had a very low activity. Co-60 and Eu-152 will be chosen as key nuclides for future concrete waste measurements.

\section{CONCLUSION AND FUTURE WORK}

This paper describes preliminary measurements that will be used in decommissioning project of FiR1 TRIGA research reactor. Computational estimates of total activity inventories have been published earlier [7], but measured values are required to verify the results and to plan safety of workers during dismantling and all legal requirements for waste packaging and final disposal.

The presently completed measurements support earlier calculations, although only low activity samples have been studied so far. To determine the radiological condition of the facility in detail, samples need to be taken also from more active parts with a systematic sampling plan. Work will continue with collecting more samples from different parts of the facility (especially from biological shield concrete) and from material that have not been drilled yet, such as steel inside the tank, Fluental moderator and beam tube plugs. This requires a detailed sampling plan and wellestablished measurement methods. Moreover, beta active nuclides such as Ni-63, Fe-55 and Ca41 need to be measured via chemical dissolving, radiochemical separation and liquid scintillation counting. Only after that, full nuclide vectors and scaling matrices can be reported. 


\section{ACKNOWLEDGEMENTS}

Authors thank Kai-Roger Hurme from University of Helsinki (Faculty of Agriculture and Forestry ) radioisotope laboratory for help with the Junitek Oxidizer, Cristian Lungu from National Institute for Laser Plasma and Radiation Physics in Bucharest and Jari Likonen from VTT for coordinating the full combustion measurements at IFIN-HH, senior scientist Pertti Koskinen from VTT Expert Services for concrete composition measurements, Tarryn Ackermann for ISOCS gammaspectrometry measurements of concrete and aluminum and the staff at HR ICP-MS laboratory at VTT.

\section{REFERENCES}

[1] Auterinen, liro; Salmenhaara, Seppo, Current utilization and long term strategy of the Finnish TRIGA research reactor FiR 1, Proceedings of the 4th World TRIGA Users Conference, Lyon (France); 7-10 Sep 2008, INIS-FR--08-1293, 2008b.

http://www.iaea.org/inis/collection/NCLCollectionStore/_Public/40/007/40007431.pdf

[2] R.J. Rosenberg, Instrumental activation analysis of 11 lanthanide elements in Apollo 12 Lunar Samples. Radiochem. Radioanal. Letters, vol. 6, 45, 1971.

[3] S. Savolainen et al., Boron neutron capture therapy (BNCT) in

Finland: Technological and physical prospects after 20 years of experiences, Physica Medica 29(3), pp. 233-248, 2013 
[4] I. Auterinen, S.E.J Salmenhaara, The 250 kW FiR 1 TRIGA Research Reactor - International Role in Boron Neutron Capture Therapy (BNCT) and Regional Role in Isotope Production, Education and Training, Research Reactors: Safe Management and Effective Utilization Proceedings of an international conference held in Sydney, Australia, 5-9 November 2007, Proceedings of an International Conference organized by the International Atomic Energy Agency (IAEA), IAEA-CN-156, 2008a.

http://www-

pub.iaea.org/MTCD/publications/PDF/P1360_ICRR_2007_CD/datasets/I.H.\%20Auterinen.html

[5] I. Auterinen et al., Metamorphosis of a 35 Years Old TRIGA Reactor into a Modern BNCT Facility, Proc. of the Eighth International Symposium on Neutron Capture Therapy for Cancer, La Jolla, California, USA, Sept. 1998

[6] P. Kotiluoto et al., Shielding Design Calculations for the Finnish BNCT Facility, Proc. of the Eighth International Symposium on Neutron Capture Therapy for Cancer, La Jolla, California, USA, Sept. 1998

[7] A. Räty and P. Kotiluoto, FiR 1 TRIGA Activity Inventories for Decommissioning Planning, Nuclear Technology, Vol. 194, pp. 28-38, April 2016

[8] International Atomic Energy Agency, Radiological Characterization of Shut Down Nuclear Reactors for Decommissioning Purposes, IAEA Technical Report Series 389, Vienna 1998.

[9] X-5 Monte Carlo Team, "MCNP - A General Monte Carlo N-Particle Transport Code, Version 5", Los Alamos National Laboratory, LA-UR-03-1987 (2003) 
[10] I.C. Gauld et al., "ORIGEN-S: A Scale System Module to Calculate Fuel Depletion, Actinide Transmutation, Fission Product Buildup and Decay, and Associated Radiation Source Terms", Oak Ridge National Laboratories ORNL/TM-2005/39, version 6.1 (2011).

[11] Radiation and Nuclear Safety Authority STUK, "Predisposal management of low and intermediate level nuclear waste and decommissioning of a nuclear facility", YVL guide D.4 ISBN 978-952-309-125-2 (2013)

[12] In Situ Gamma Spectroscopy with ISOCS, an In Situ Object Counting System. Canberra Application Note [Online] [access 2015, September 7]; Available: http://www.canberra.com/literature/gamma_spectroscopy/application_notes/InSitu-ISOCSM2352.pdf

[13] GenieTM 2000 Basic Spectroscopy Software. Canberra Industries [Online] [access 2015, September 7]; Available: www.canberra.com/products/radiochemistry lab/.../G2K-BasicSpect-SSC40220.pdfG2K-BasicSpect:

[14] T. Carlsson et al, Chemical aspects on the final disposal of irradiated graphite and aluminium, VTT Technology 156, ISBN 978-951-38-8095-8, 2014

[15] T. Ackermann, Methods for the Radiological Characterisation of the FiR 1 TRIGA Research Reactor Decommissioning Waste, M.Sc. thesis, Stellenbosch University, March 2017. 